\title{
Ann Radcliffe, Le Roman de la forêt
}

\section{Michel Arrous}

\section{(Q) OpenEdition}

\section{Journals}

\section{Édition électronique}

URL : http://journals.openedition.org/studifrancesi/3775

DOI : 10.4000/studifrancesi.3775

ISSN : 2427-5856

\section{Éditeur}

Rosenberg \& Sellier

\section{Édition imprimée}

Date de publication : 1 décembre 2012

Pagination : 583

ISSN : 0039-2944

\section{Référence électronique}

Michel Arrous, « Ann Radcliffe, Le Roman de la forêt », Studi Francesi [En ligne], 168 (LVI | III) | 2012, mis en ligne le 30 novembre 2015, consulté le 06 mars 2021. URL : http://journals.openedition.org/ studifrancesi/3775 ; DOI : https://doi.org/10.4000/studifrancesi.3775

Ce document a été généré automatiquement le 6 mars 2021.

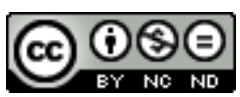

Studi Francesi è distribuita con Licenza Creative Commons Attribuzione - Non commerciale - Non opere derivate 4.0 Internazionale. 


\title{
Ann Radcliffe, Le Roman de la forêt
}

\author{
Michel Arrous
}

\section{RÉFÉRENCE}

ANN RADCLIFFE, Le Roman de la forêt, édition de Jérémie GRANGÉ, Paris, Classiques Garnier, 2011, pp. 412.

1 On doit remercier Jérémie Grangé d'avoir ressuscité Le Roman de la forêt (1791) par une traduction nouvelle et complète. Le premier des trois chefs-d'œuvre d'Ann Radcliffe méritait depuis longtemps cette réactualisation! Le traducteur a suivi le texte de la dernière édition parue du vivant de l'auteur et s'est refusé à un «illusoire effort de modernité», tout à son souci de respecter les traits caractéristiques du style de Radcliffe. Alors que les lecteurs français disposent de bonnes traductions de L'Italien, ou le Confessionnal des pénitents noirs (A Sicilian Romance) et des Mystères d'Udolphe, il n'en existait aucune de ce roman, à part de fort médiocres ou d'incomplètes publiées sous le titre La Forêt ou l'abbaye de Saint-Clair, en 1794, 1830-1831 et, signalons-le au traducteur, en 1868, à une époque où les romans de Mrs Radcliffe connaissaient une nouvelle vogue.

2 En dépit du titre - The Romance of the Forest -, Ann Radcliffe a rangé son ouvrage, comme tous les autres d'ailleurs, dans la catégorie «novel», distinction dont la pertinence ne saute pas aux yeux, surtout si l'on se rappelle les définitions des termes «romance» et «novel» arrêtées par Clara Reeve et Walter Scott. J. Grangé suppose non sans raisons que le lecteur pouvait ainsi, dès la première page, se faire une idée du texte en l'appréhendant comme un roman gothique, alors qu'on a plutôt affaire à un roman sentimental. Au lieu de respecter les exigences du genre gothique, Radcliffe enchevêtre les genres, pratique une esthétique $d u$ contraste et fait un usage original du fantastique, en fait du «surnaturel expliqué». J. Grangé (pp. 13-23) propose d'y voir un roman de formation, un apprentissage marqué par la mélancolie et un roman philosophique sous la forme d'un dialogue avec Rousseau, plus précisément avec l'auteur des Rêveries et de Julie. 
3 À cela s'ajoute, et J. Grangé fait bien de le mentionner, l'influence de la lecture de Burke que Maurice Lévy avait déjà relevée (Le Roman «gothique» anglais, 1764-1824, 1968): dans l'expérience du sublime, l'individu s'élève ou sort de lui-même, et dépasse l'immédiat. Après avoir situé Ann Radcliffe dans la littérature de son temps, J. Grangé aurait pu brièvement rappeler les innombrables imitations dont elle fit l'objet en France et, dans le cas particulier de ce roman dont l'auteur nous dit qu'il prend son origine dans les Causes célèbres de Gayot de Pitaval, signaler qu'il n'est pas sans lien avec Alexis ou la Maisonnette dans la forêt, grand succès de Ducray-Duminil en 1789. Sans doute a-t-il eu en France une fortune moindre que Les Mystères d'Udolphe (1794) et L'Italien (1797) qui le surpassèrent; néanmoins, suivant en cela Stendhal, on recommandera sa lecture pour «secouer l'imagination et tonifier l'âme». 